ciedades diferentes, así lo ilustran. El trabajo de Sol Gastaldi y Sergio G. Eissa pone de relieve algunas inconsistencias del despliegue militar argentino con la ley de Defensa Nacional sancionada en 2005. Los autores llaman la atención respecto de la persistencia de estrategias de despliegue territorial derivadas de enfoques de defensa nacional con preocupación central en un enemigo interno, en contraste con la orientación normativa hacia el planeamiento estratégico de acuerdo a las transformaciones registradas en los escenarios nacional, regional e internacional. Por su parte, el análisis de Martha Cecilia Jaramillo Cardona y Salvador Adame Gómez llama la atención sobre la persistencia de desigualdades de género en las políticas de protección de áreas naturales en el estado de Sonora (México), que afectan en particular a las mujeres cabeza de familia dedicadas a

la producción agrícola.

Arturo A. Fernández (1940-2017)

El equipo de producción de la Revista Perspectivas de Políticas Públicas informa con tristeza el fallecimiento de quien fue, desde el primer número, miembro distinguido del Consejo Asesor. Politólogo de merecido renombre dentro y fuera de Argentina, docente e investigador en universidades del país y el exterior, presidente en dos oportunidades de la Sociedad Argentina de Análisis Político, merecidamente galardonado con premios y distinciones, a lo largo de cuatro décadas impulsó de manera relevante el desarrollo de la Ciencia Política nacional y la formación de docentes e investigadores que a partir de esa guía emprendieron sus propios y exitosos caminos.Vamos a extrañarlo.

Carlos M.Vilas Director, RPPP

\title{
El neoliberalismo puesto en perspectiva. Para una revisión de nuestras concepciones críticas
}

Neoliberalism in perspective. For a review of our critical conceptions

Pablo Martín Méndez Doctor en Filosofia (UNLa). Becario Postdoctoral (CONICET) Política (UBA).

Profesor titular de Fundamentos de Ciencia Política (UNLa).

Fecha de recepción: 23.4.17

Fecha de aceptación 12.8.17

\section{Resumen}

Este artículo pretende abrir algunos puntos necesarios de debate para avanzar en la re-conceptualización del "neoliberalismo", desplazando el análisis crítico un poco más allá de los supuestos habituales. ¿Cómo entendemos hoy al neoliberalismo? ¿En qué nos apoyamos para criticarlo? Al neoliberalismo se lo suele identificar en gran parte de la literatura con una suerte de regreso hacia el pasado, ya sea en la forma de la ortodoxia económica o bien del intervencionismo represivo. Sin dar respuestas últimas y definitivas, nos preguntamos aquí cómo los programas neoliberales de gobierno ganan una amplia adhesión en la población, cómo interpelan nuestras conductas y creencias, más allá de la ortodoxia económica y la represión.

Palabras clave: programas neoliberales de gobierno - genealogía - libertad de emprendimiento crítica.

\section{Abstract}

This article aims to open some points of debate to advance in the re-conceptualization of "Neoliberalism". In other words, we want to shift critical analysis a bit beyond most common assumptions. What do we understand today by Neoliberalism? On what basis do we criticize it? 
Neoliberalism is usually identified with some kind of return to the past, either in the form of economic orthodoxy or repressive interventionism. Without giving definitive answers, we ask here how neoliberal government programs reach a wide adherence in the population, how they aim to speak to our behaviours and beliefs, beyond economic orthodoxy and repression.

Key words: neoliberalism - government programs - genealogy - freedom of entrepreneurship - criticism.

\section{Introducción}

El "neoliberalismo" se ha convertido últimamente en un concepto ambiguo e incluso problemático en sí mismo. Su uso no sólo resulta atractivo, sino que además parece ineludible en cualquier crítica de la actualidad. Su definición, en cambio, presenta enormes dificultades e inconsistencias. No hay un acuerdo común sobre los límites y los alcances del concepto de neoliberalismo. Algunos críticos contemporáneos hablan de la imposición de una doctrina económica que, como tal, desconoce o deja de lado las variables sociales, políticas y culturales. Otros advierten la presencia del neoliberalismo en casi todas partes, asimilándolo a fenómenos tan vastos como el imperialismo o la globalización (Harvey 2015; Jessop 2002). Nadie sabe bien dónde el neoliberalismo empieza y termina; nadie puede responder tampoco en qué punto las teorías, las prácticas gubernamentales y las variables sociales se cruzan para dar lugar al fenómeno neoliberal. Por una u otra razón, el neoliberalismo deviene en una suerte de "concepto tramposo", más pronto a generar confusiones que a estimular el debate académico y político (Brenner, Peck y Theodore 2010; Venugopal 2015)

Quizá sea el debate lo que todavía hace falta practicar en Argentina y en gran parte de América Latina, donde sólo muy recientemente hemos comenzado a salir de las concepciones "negativas" sobre el neoliberalismo. Nos referimos a la asimilación directa de las políticas neoliberales con la desregulación económica, el ajuste fiscal y la restricción de las protecciones sociales. Esta operación reduccionista, que según Boas y Gans-Morse (2009) resulta muy frecuente en los estudios latinoamericanos, es el primer punto a problematizar en el presente artículo. ${ }^{1}$ El segundo punto de discusión está en la tendencia, también bastante común, a establecer una identificación casi excluyente entre las políticas neoliberales y la represión estatal, lo cual no sólo se observa en las críticas de tono sociológico o político, sino además en las perspectivas antropológicas al estilo de Loïc Wacquant (2012), o bien en críticas epistemológicas como la de Ricardo Gómez (1995).

Así planteadas las cosas, nuestro objetivo consiste en hacer la crítica a algunos conceptos y definiciones usuales de neoliberalismo, mostrando sus posibles límites y abriendo a la par ciertos puntos de debate. Aquello que nos guía no es en absoluto una pretensión de "neutralidad valorativa" o una estricta vocación de cientificidad, como si en el límite se tratase simplemente de des-ideologizar las actuales críticas al neoliberalismo en pos de un análisis más objetivo y desinteresado. Muy por el contrario, lo que intentamos hacer es complementar e incluso potenciar tales críticas.

La revisión de las críticas vigentes sobre el neoliberalismo resulta imprescindible especialmente hoy día, cuando en Argentina y en América Latina se están dando fenómenos difíciles de analizar con las herramientas conceptuales disponibles. A pesar de las constantes crisis financieras, de los repetidos fracasos económicos, de las resistencias populares y la búsqueda de proyectos políticos alternativos, los programas neoliberale de gobierno no sólo persisten en el tiempo, sino que además parecen arraigarse cada vez más en la población. Pues bien, ¿cómo explicamos esto?

Al menos desde nuestro punto de vista, el problema no reside en la escasez de análisis e interpretaciones; en cualquier caso, creemos que hace falta ensayar y construir nuevas formas de argumentación, sin que ello implique descartar o restar valor a las formas explicativas más frecuentes. Ni las ciencias sociales en general, ni la ciencia política en particular, permanecen ajenas a semejante tarea. Pero aclaremos que tampoco es nuestra intención discutir con un determinado posicionamiento teórico y metodológico. Antes bien, la idea es desplazar el análisis un poco más allá de los supuestos que subyacen en varias de las críticas actuales sobre el neoliberalismo.

Aquí nos conformaremos con identificar dos de esos supuestos. El primero consiste en introducir al neoliberalismo en toda una suerte de "historia cíclica" o circular, donde los períodos conservadores se alternarían indefinidamente con ciclos progresistas. Puesto en estos términos, el neoliberalismo es leído como un capítulo más en la eterna lucha entre las minorías mezquinas y las mayorías populares, las clases opresoras y las masas oprimidas, los poderosos y los despojados de casi todo, inaugurando o reabriendo un ciclo que ya pasó en otros momentos y que se repetirá hasta el fin de la historia. E segundo supuesto, relacionado con el primero y también presente en una inmensa variedad de análisis, nos lleva a concluir que los proyectos neoliberales, precisamente por su impopularidad y por su tendencia a generar exclusión, sólo son posibles mediante la represión y la violencia. Para que las masas acepten lo inaceptable, resultaría necesario copar las calles con policías, sofocar toda posible resistencia, regimentar la sociedad entera, hasta el punto mismo de coartar la mayor parte de las libertades civiles. Esta 
interpretación no es injustificada, sino que se apoya en innumerables experiencias y hechos de la vida cotidiana. La represión estatal, se mire por donde se mire, parecería constituirse en la ultima ratio de cualquier política neoliberal.

Puede que sea David Harvey, un crítico marxista muy leído en América Latina, quien mejor resuma la serie de posturas que aquí intentamos revisar. Desde su perspectiva, el análisis del neoliberalismo debe contemplar dos dimensiones distintas. Por un lado, está la teoría o la "ortodoxia neoliberal", basada principalmente en la desregulación de los mercados, la privatización de las empresas públicas y el retroceso del Estado en las áreas de provisión social. Por el otro, hay un proceso real de "neoliberalización" donde el Estado se desvía de las pautas ortodoxas para intervenir en favor de los negocios y la especulación financiera, reprimiendo toda oposición a los intereses corporativos:

Para protegerse frente a sus grandes miedos -el fascismo, el comunismo, el socialismo, el populismo autoritario e incluso el gobierno de la mayoría- los neoliberales tienen que poner fuertes límites al gobierno democrático $y$ apoyarse, en cambio, en instituciones no democráticas ni políticamente responsables (como la Reserva Federal o el FMI) para tomar decisiones determinantes. Esto crea la paradoja de una intensa intervención estatal y el gobierno por parte de élites y de "expertos" en un mundo en el que se supone que el Estado no es intervencionista. (...) Frente a los movimientos sociales que buscan intervenciones colectivas, el Estado neoliberal se ve obligado a intervenir, en ocasiones de manera represiva, negando, por lo tanto, las mismas libertades que supuestamente defiende. (Harvey 2015:78-79).

¿Qué entendemos entonces por neoliberalismo? Al neoliberalismo se lo suele identificar actualmente con una vuelta hacia lo peor del pasado, ya sea porque allí encontramos a reactivación de la ortodoxia económica, cuyo único objetivo consistiría en liberar las fuerzas naturales del mercado, o bien porque las políticas neoliberales nos huelen de una manera u otra a represión organizada, vale decir, a una violencia dirigida desde el Estado y los aparatos paraestatales contra la sociedad civil. Para nosotros, el neoliberalismo no se reduce necesariamente ni a una cosa ni a la otra: ni al retorno de la ortodoxia, ni tampoco al simple aumento de la represión estatal. Hay que preguntar cómo el neoliberalismo gana adhesión en la población, cómo se arraiga en nuestros comportamientos y creencias, más allá de la ortodoxia económica y la represión de Estado. No es que se trate de negar esos fenómenos; al contrario, pensar al neoliberalismo más allá de la ortodoxia y la represión equivale a preguntarse también cómo una cosa y otra son en el límite posibles.

\section{Más allá de la ortodoxia económica}

El neoliberalismo sobre el cual hablaremos aquí no es un fenómeno general y omnicomprensivo, equiparable a realidades tales como el "capitalismo", la "globalización" o el "imperialismo". Antes bien, se trata de abordar al neoliberalismo por sus aspectos programáticos o propositivos, concibiéndolo como un "criterio de inteligibilidad" sobre las prácticas y las relaciones socioeconómicas. Desde esta perspectiva, el neoliberalismo es mucho más y a la vez mucho menos de lo que estamos habituados a pensar. Es mucho más porque, a nivel programático, el neoliberalismo funciona como un modo específico de descifrar las relaciones entre el mercado, las intervenciones estatales y las libertades de los individuos; pero también mucho menos, porque no hay programa neoliberal capaz de determinar esas relaciones en todos sus aspectos reales y concretos. ${ }^{2}$ Los programas neoliberales no explican la realidad en su totalidad, puesto que nunca se aplican en forma total y homogénea. Dicho en otros términos, no hay una realidad a la cual podamos calificar de "neoliberal"; lo que hay en todo caso son variables neoliberales que intervienen en nuestro presente, actuando en contradicción o en conjunto con otras formas de descifrar e intervenir la realidad misma.

Hechas estas aclaraciones, jcómo entendemos entonces a los programas neoliberales? ¿cuáles serían sus propuestas o contenidos concretos? La respuesta a estas preguntas no es sencilla; sobre todo porque requiere posicionarnos en los márgenes de las concepciones más aceptadas y difundidas acerca del neoliberalismo. Existe una suerte de historia convencional que relaciona al neoliberalismo con las doctrinas económicas del liberalismo decimonónico. Varios críticos hablarán de un retorno hacia la famosa "mano invisible" de Adam Smith (Boron 2003), mientras que otros pensarán en la recuperación de la "teoría neoclásica" (Bresser-Pereira 2009; Saad-Filho y Johnston 2005). A través de distintos caminos, todos coincidirán en suponer que el neoliberalismo es la predominancia de las fórmulas, las ecuaciones y las recetas económicas por sobre la realidad social, cultural y moral de un pueblo (Bourdieu 1998). Ser neoliberal implicaría comportarse entonces como un ortodoxo, vale decir, como alguien que, al adherir tan fuertemente a una determinada doctrina o conjunto de ideas, deja de percibir otras realidades posibles, en tal caso: las realidades extraeconómicas. Pues bien, ¿vamos a conformarnos con esa concepción crítica?, ¿acaso el neoliberalismo se reduce inevitablemente a la ortodoxia económica?

A la historia convencional habría que proponerle, como modo de estimular y enriquecer el debate, una genealogía sobre el neoliberalismo. La genealogía, decía Michel Foucault, es un instrumento de análisis que pone la mirada en las partes más grises y empolvadas de la historia, adentrándose en las condiciones de emergencia y mutación de nuestros sistemas de pensamiento, nuestros regímenes de verdad, nuestros modos de conducirnos y de ser conducidos por otros, nuestras libertades (Foucault 1971, 2013). 
Se trata de desmenuzar toda interpretación lineal de la historia, en el intento de abrir espacios allí donde las cosas parecen perfectamente continuas o sucesivas. La genealogía, sostendremos nosotros, se ahorra en casi todo momento los análisis circulares de nuestra actualidad, sobre todo aquellos donde los ciclos progresistas perecerían sucederse infinitamente con los ciclos conservadores.

Por cuanto al neoliberalismo respecta, el método genealógico deberá mirar un poco más allá de ciertos puntos históricos bastante recurrentes. Nos referimos fundamentalmente a Friedrich Hayek y Milton Friedman, que son considerados por muchos como la fuente primaria de todo el pensamiento neoliberal. No hay que ir demasiado lejos para advertir que estos intelectuales, calificados a menudo de ortodoxos, participan de un amplio programa de reforma social y cultural. Ello ya es evidente en el conocido libro The Road to Serfdom (1944) de Hayek, particularmente en los pasajes donde la promoción de la libertad económica no aparece como un objetivo aislado o cerrado en sí mismo, sino que se vincula al intento de recuperar la cultura y los valores abandonados con el intervencionismo de Estado, el socialismo y finalmente el totalitarismo. Década más tarde, cuando los programas neoliberales se difundan por todo el mundo, la misma Margaret Thatcher lanzará una frase enigmática: "Economics are the method. The object is the change of soul" ("La economía es el método. El objetivo es cambiar el alma").

Lo cierto es que los aspectos más "reformistas" del neoliberalismo, incluyendo la dimensión social, cultural y hasta espiritual de sus proyectos de gobierno, se perciben con mayor claridad en un conjunto de pensadores hoy en día olvidados por la historia de las ideas. Estamos hablando economistas tales como Wilhelm Röpke, Walter Eucken y Alfred Müller-Armack, cuyos escritos sólo muy recientemente han sido tomados en cuenta por el análisis genealógico del neoliberalismo. ${ }^{3}$ La selección no es azarosa; por el contrario, los trabajos de Röpke, Eucken y Müller-Armack están asociados de diferentes maneras al "Ordoliberalismo alemán”, "La escuela de Friburgo"y la "Economía social de mercado" de mediados del siglo XX. En estas corrientes de pensamiento, surgidas en Europa Occidental y difundidas rápidamente hacia otros lugares del mundo, algunos estudiosos contemporáneos encuentran la versión más "positiva” del neoliberalismo, ya sea por el hecho de que sus miembros se identificaban con la necesidad de fundar un "nuevo liberalismo", o bien porque sus programas políticos no quedan limitados en la mera desregulación de los mercados, la privatización de las empresas públicas y el desguace del Estado (Boas y Gans-Morse 2009:145-147; Peck: 2008:19-22). ${ }^{4}$

La especificidad de esa vertiente de neoliberalismo -o aquello que la haría diferir de las posturas hoy en día más conocidas- está en la idea de que la competencia de mercado no funciona por sí misma, como si se fuese un fenómeno espontáneo o un hecho natural, sino que depende más bien de toda una serie condiciones artificialmente establecidas. Se trata de condiciones de todo orden, desde la reglamentación jurídica provista por el
Estado hasta las costumbres y las formas de vida de la población (Eucken 1947; MüllerArmack 1962). Son los factores extra-económicos que requeriría el buen funcionamiento de la economía propiamente dicha. Röpke definirá a esas condiciones como un "marco antropológico-sociológico": "La economía de mercado necesita un sólido trasfondo al que llamaremos marco antropológico-sociológico. Si este marco se rompe, tampoco es ya posible la economía de mercado. En otras palabras: la economía de mercado no es todo" (Röpke 1949a:38).

Así pues, el neoliberalismo no siempre se limita a desregular los mercados, sino que a veces va mucho más lejos. El objetivo consiste en intervenir en el espesor de la trama social misma, acondicionándola a las necesidades de funcionamiento de la economía de competencia. Ese proyecto, a todas luces más político que estrictamente económico, tiene enormes implicancias gubernamentales: primero y ante todo, porque conlleva una nueva manera de juzgar las posibles intervenciones de gobierno.

Se ha creído que el neoliberalismo conduce necesariamente hacia un "Estado Mínimo" (Bresser-Pereira 2009), cuando en realidad ocurre que el problema no reside tanto en la "cantidad" de intervenciones como en su "cualidad": "La conveniencia de una mayor o menor actividad económica del Estado es un problema que muchas veces queda desatendido. No es un problema cuantitativo, sino cualitativo" (Eucken 1956:470). Para decirlo en otros términos, el problema nunca está en que los gobiernos intervengan demasiado; antes bien, lo que se debe saber es si las intervenciones posibles resultan o no conformes con la competencia de mercado. Como indicará Müller-Armack, las intervenciones conformes son aquellas que respetan el mecanismo de precios generado por la competencia y las acciones de regulación que de allí se desprendan: "esto significa medidas destinadas a asegurar la finalidad del mercado sin interferir negativamente en su mecanismo" (Müller-Armack 2011 [1956]:18). Intervenciones disconformes son en cambio las que centralizan la economía mediante diferentes reglamentaciones y controles, sustituyendo el mecanismo de precios por un orden planificado o "colectivista". 5

De modo tal que poco importa la cantidad de intervenciones desplegadas: mientras se apunte hacia las condiciones artificiales de la competencia, y no directamente al mecanismo de precios, serán siempre intervenciones conformes. $\mathrm{Al}$ analizar ese nuevo criterio de gobierno con el suficiente detenimiento, vemos la posibilidad de una intervención gubernamental "indefinidamente activa"; una política que, sólo a condición de no tocar los delicados mecanismos del mercado, puede tocar casi todo, interviniendo de hecho en la sociedad entera. ${ }^{6}$

\section{Más allá de la represión}

Podemos aceptar entonces que neoliberalismo, en lo que tiene de propositivo o de programático, da lugar a toda una serie de intervenciones políticas sobre las condiciones 
extra-económicas de la economía de competencia. Ahora bien, ¿cuál sería el carácter de esas intervenciones?, ¿se trata únicamente de "intervenciones represivas"? Precisamente en este punto, muchos críticos contemporáneos advierten que los programas neoliberales sólo son posibles mediante la represión generaliza de la disidencia, remarcando así una tensión irresoluble entre las propuestas o los proyectos gubernamentales y las prácticas efectivas. Las consideraciones de Ricardo Gómez resultan bastante ilustrativas al respecto:

(...) el neoliberalismo no es verdaderamente liberal, sino una forma de un fuerte intervencionismo estatal con un bonus: la intervención es siempre a favor de las pocas personas más ricas y poderosas. Otra contradicción importante es la que existe entre la demanda de intervención no estatal para ayudar a los pobres y corregir las desigualdades y el hecho de pedir al Estado que intervenga con dinero para el pago de las fuerzas más represivas - policía, ejército, paramilitares- (Gómez: 2014:27).

Los hechos cotidianos confirman de diversas maneras que los gobiernos identificados con el neoliberalismo se apoyan en la represión de vastos sectores de la población. La represión no sólo está dirigida hacia los opositores políticos y los movimientos sociales, sino además hacia los trabajadores desocupados y precarizados, las minorías étnicas, los inmigrantes y todas aquellas agrupaciones que planteen resistencia al orden propuesto. Ninguna crítica sensata podría negar una realidad semejante. Sin embargo, lo que no conviene decir muy a la ligera es que el último recurso del neoliberalismo, su única forma de intervenir en la sociedad y de hacer realizables sus programas, se encuentra en la represión misma. Esta clase de reduccionismo debería evitarse en la medida de lo posible; sobre todo por las serias consecuencias que suele acarrear para el diagnóstico de nuestro presente. Porque en efecto, ¿̇cómo se resolvería la contradicción entre el anti-intervencionismo neoliberal y el intervencionismo represivo de los gobiernos concretos? ¿Cuál sería el horizonte último de un programa que sólo funciona a costa de incrementar la represión en la sociedad? Arribamos aquí a uno de los puntos más comunes aunque menos revisados por las críticas contemporáneas, y es la idea que el neoliberalismo está en última instancia emparentado con la dictadura:

Resulta necesario, por una parte, evitar la transformación del estado en un estado intervencionista; por otra parte, hace falta un poder estatal mayor que sea capaz de acallar los reclamos de aquellos que exigen la intervención del estado en la economía. (...) Si se continúa con esta línea de argumentación, se concluye que no queda afuera, al menos en principio, la necesidad de un gobierno con poderes absolutos, es decir una dictadura (Gómez 1995:180).
Esta es una de las ideas que han quedado instaladas en algún punto de nuestro sentido crítico. La asociación entre neoliberalismo y dictadura viene siendo remarcada desde hace décadas; casi desde el mismo momento en que las políticas económicas de corte neoliberal se difundían por todo el mundo.

En las décadas de 1960 y 1970, los debates latinoamericanos sobre política económica concedían un sentido más "positivo" al neoliberalismo, asociándolo a menudo con la experiencia de la Alemania Occidental de posguerra. Pero ello cambia drásticamente durante los años setentas, cuando el término comienza a utilizarse para describir las reformas económicas implementadas en el Chile de Augusto Pinochet y en otros países del Cono Sur. A partir de entonces, el neoliberalismo adquiere una connotación completamente negativa, hasta el punto en que deja de ser utilizado por los mismos economistas y funcionarios promotores del mercado (Boas y Gans-Morse 2009; Venugopal 2015).

No debemos ignorar la vinculación histórica entre el neoliberalismo y los regímenes dictatoriales de América Latina, aunque tampoco hay que buscar allí el criterio casi exclusivo para analizar la proyección de las políticas e intervenciones neoliberales sobre la sociedad. La dictadura no es el horizonte último del neoliberalismo; antes bien, hace falta percibir la operatividad de otras variables o vertientes neoliberales en nuestro presente, observando hasta qué punto despiertan la adhesión en una parte considerable de la población.

\subsection{La sospecha neoliberal contra el intervencionismo económico}

Hay dos cosas que ninguna genealogía debería perder de vista. La primera es que el neoliberalismo emerge históricamente como una suerte de "rebelión" contra las experiencias dictatoriales de las décadas de 1930 y 1940, especialmente en la forma del fascismo italiano y el nazismo alemán. Esto se aprecia en cualquier texto de la época, desde Hayek hasta Röpke, desde los neoliberales austríacos y alemanes hasta los norteamericanos de la Escuela de Chicago. La crítica neoliberal al fascismo no tiene nada de neutral ni de inocente; al contrario, de allí se desprende un enorme efecto político, que consiste en establecer una línea de continuidad, una relación de parentesco, entre los regímenes fascistas y toda posible acción gubernamental sobre la economía. No importa si son keynesianos, welfaristas, socialistas o comunistas: bastará con que procuren corregir y regular las oscilaciones económicas, interviniendo directamente en los mecanismos y resortes de la competencia, para que aviven al fantasma del fascismo. Se trata del "camino de servidumbre" sobre el que tanto ha hablado Hayek; aquel que comienza con la planificación y el intervencionismo estatal en la economía:

La planificación conduce a la dictadura, porque la dictadura es el más eficaz instrumento de coerción y de inculcación de ideas y, como tal, indispensable para hacer po- 
sible una planificación central en gran escala. El conflicto entre planificación y democracia surge sencillamente por el hecho de ser ésta un obstáculo para la supresión de la libertad, que la dirección de la libertad económica exige (Hayek 2011:130).

Puesta en estos términos, cualquier intervención estatal posible, venga de donde venga y tenga la orientación que tenga, terminaría indefectiblemente en lo peor: "un Estado monolítico totalitario, donde el gobierno y el Estado son todo, y el individuo nada" (Röpke: 1960: 16).

A la crítica contemporánea todavía le queda por preguntar hasta dónde llega esa continua sospecha contra el intervencionismo estatal en la economía, que sin duda no termina en los primeros neoliberales de mediados del siglo XX, sino que se difunde a través de las editoriales de la prensa, los discursos de políticos y economistas, los informativos de radio y de televisión, y otros tantos canales de formación y orientación de la opinión pública de nuestros días. Se podría trazar toda una historia sobre las variaciones de la sospecha anti-intervencionista promovida desde el neoliberalismo, incluyendo sus formas de aparición y reaparición en distintos momentos y lugares del mundo. Lo que ayer era una amenaza de fascismo, se convertiría años más tarde, tras la Segunda Guerra Mundial, en una constante amenaza de comunismo. En América Lantina, tal tipo de parentescos fue tempranamente señalado por los primeros neoliberales europeos.Ya en 1960, en el marco de un ciclo de conferencias brindado en Buenos Aires para el Foro de la Libre Empresa, Röpke se encargaba de dejarlo bien claro:

(...) tanto el nacionalsocialismo como el comunismo han constituido formas extremas de lo que designamos en términos políticos como totalitarismo. (...) El economista precisa recordar, antes que nada, que el comunismo no es un sistema económico sino un fenómeno político militar. $Y$ si queremos mejorar nuestro coeficiente moral en Occidente en esta gran lucha mundial entre comunismo y mundo libre, lo primero que debemos hacer siempre es tener claridad de pensamiento en cuanto a lo que el comunismo realmente implica (Röpke 1960:72).

El neoliberalismo latinoamericano ha construido sus propios fantasmas intervencionistas durante más de medio siglo. Desde la década de 1970, viene reemplazado al viejo fantasma comunista por el famoso y hoy más efectivo fantasma del "populismo". Basta consultar al respecto los escritos de intelectuales como Ricardo Zinn, cuyo pensamiento y trayectoria han dejado una importante impronta en la historia del neoliberalismo argentino:
(...) en el populismo la minoría debe ser perseguida, amedrentada y destruida para procurar la uniformidad inbecilizadora que tanto complace a la emoción colectiva de la masa (...) El nazismo y el stalinismo son dos grandes experiencias populistas, en ambas se operó exclusivamente con el número máximo por la eliminación fisica o el sometimiento ideológico de los aterrados discrepantes (Zinn 1976:47). ${ }^{7}$

Esta forma de discursividad, donde el populismo, el comunismo y el fascismo quedan unidos por el delgado hilo de la intervención estatal sobre la economía, no sólo ha servido para fundamentar el accionar de algunos gobiernos militares en América Latina, sino que además ha sido utilizada en democracia, como estrategia para la construcción de mayorías electorales. Es una cuestión que cualquier análisis crítico debería tener en cuenta. Nos referimos a la construcción y la sedimentación de unas determinadas "condiciones de aceptabilidad" en las opiniones del público, más allá de los gobiernos y los regímenes políticos. ${ }^{8}$

En efecto, al fomentar la asociación entre la intervención gubernamental sobre la economía y la amenaza fascista, comunista o populista, los neoliberales crean todo un marco de adhesión para su propio programa de gobierno; más aún, hacen creer que no hay ninguna alternativa posible por fuera de dicho programa. Ayer la tiranizada isla de Cuba hoy el infierno de Venezuela. Si recabásemos en la actual retórica del neoliberalismo latinoamericano, encontraríamos que el punto culmine de toda intervención del Estado sobre la economía reside en el "chavismo" venezolano. Ese sería el ejemplo más vivo y más nítido del populismo contemporáneo; allí estaría también el destino que los gobiernos deberían evitar a toda costa, incluso si ello requiere de políticas económicas declaradamente restrictivas. De hecho, muchos economistas, intelectuales y funcionarios esperan que el pueblo acepte el ajuste y la austeridad antes de caer en el "oscuro abismo" del régimen chavista. El escritor peruano Mario Vargas Llosa brinda un claro ejemplo de esta clase de retórica, coincidiendo en varios puntos con las definiciones de los primeros neoliberales, especialmente los neoliberales alemanes:

El pueblo venezolano se equivocó al darle apoyo a Chávez, un señor carismático. En Perú se equivocaron con Alberto Fujimori, que impuso una dictadura sanguinaria, lo hicieron en Alemania con Hitler. Afortunadamente se puede rectificar. Todos los pueblos se han equivocado, lo que no hay es que persistir en el error. (...) No se puede ser neutral ante la peste bubónica, que amenaza 
con extenderse, porque el colectivismo y el estatismo tienen la vocación de extenderse (Vargas Llosa: 2014).

Sin lugar a dudas, el caso de Venezuela no sólo requiere de un profundo y riguroso análisis, sino además de diferentes contribuciones críticas. La cuestión está en que toda crítica posible, como bien deja entreverVargas Llosa, se plantea desde alguna perspectiva política. Así sucede ciertamente con el neoliberalismo, cuyos programas de reforma parecen ser para muchos la única manera de evitar la debacle que acarrearía el intervencionismo económico. Hay que remarcar hasta el cansancio que esas reformas suelen venir acompañadas por medidas tan inaceptables como aquello que denuncian, incluyendo la violencia y la arbitrariedad misma. Aunque también hay que poner la atención en las prácticas discursivas del neoliberalismo latinoamericano, en particular allí donde hacen pasar lo inadmisible como parte de los "sacrificios" que la población debe aceptar en pos de la verdad.

\subsection{Neoliberalismo y neo-libertad}

Nadie va a negar aquí que las políticas neoliberales generan y en última instancia admiten la violencia, los excesos y las arbitrariedades de poder. De eso no cabe ya ninguna duda, así como tampoco que la crítica tiene la incansable tarea de denunciar la arbitrariedad en todo lugar donde se presente. Ahora bien, si queremos criticar en serio al neoliberalismo, tenemos que hacer el difícil experimento de pensar la represión y la violencia dentro de un nuevo horizonte de prácticas de gobierno, que no necesariamente se engloben bajo la palabra "dictadura". Tal es la segunda cuestión que el análisis nunca debería perder de vista. Hablamos sobre la posibilidad de que la sospecha anti-intervencionista del neoliberalismo esté acompañada por la programación de toda una serie de políticas gubernamentales sumamente activas en cuanto a capacidad de intervención y transformación del entramado social. El objetivo de esas políticas no consistiría simplemente en reprimir y acallar las posibles disidencias al orden de cosas propuesto; además de ello $-\mathrm{o}$, mejor dicho, en simultáneo con ello- se trataría de fomentar e incluso producir determinadas formas de "ser libre".

Se ha creído que las contradicciones internas del neoliberalismo generan una situación donde la libertad es reducida a su mínima expresión, quedando ubicada de hecho en el lugar de una mera "promesa", especialmente para los estratos más bajos de la población:

El autoritarismo en la imposición del mercado encaja a duras penas con el ideario de las libertades individuales. Cuanto más vira el neoliberalismo hacia lo primero, más dificil se vuelve mantener su legitimidad respecto a lo segundo y más tiene que revelar sus colores antidemocráti- cos. Esta contradicción es paralela a una creciente falta de simetría en las relaciones de poder entre las corporaciones y las personas de a pie (Harvey 2015:89).

Puede que todo lo dicho sea cierto: el neoliberalismo, se mire por donde se mire, no incrementa nuestras libertades, sino que más bien parece reducirlas y encauzarlas en una dirección determinada. Lo cual no quita sin embargo la necesidad de analizar las libertades programadas y promovidas por el neoliberalismo, aun cuando estemos lejos de hablar sobre "la" libertad en términos absolutos. No hay liberad in abstracto, sino diferentes formas de ser libre que emergen en momentos y lugares concretos, posicionándose a veces por encima de otras libertades posibles.

Por mucho que nos cueste admitirlo, el neoliberalismo fomenta creencias y deseos, maneras de actuar y de conducirse, o en fin: formas de ser libre, que pueden resultar sumamente atractivas para mucha "gente de a pie". No estamos refiriéndonos a las clásicas libertades de circulación e intercambio mercantil, cuya vigencia se relaciona más con algunas vertientes del liberalismo decimonónico que con el neoliberalismo de los siglos XX y XXI. Estamos aludiendo más bien a una libertad tan novedosa y específica como las propias ideas neoliberales. Se trata, en pocas palabras, de la libertad para ser un "emprendedor de sí mismo" (Laval y Dardot 2013; Méndez 2014). Entre el neoliberalismo alemán y la Escuela de Chicago, encontramos todo un programa de gobierno basado en el objetivo común de fomentar la autogestión o el emprendedorismo, que no se entiende aquí como una mera actividad comercial, sino ante todo como un manejo continuo de las propias destrezas, los propios saberes, las aptitudes del cuerpo, las emociones, los afectos y cualquier otro recurso incorporado que sirva para obtener mayores ingresos en el mercado. ${ }^{9}$

Habría que analizar detenidamente esa forma de ser libre, mostrando en qué difiere de otras formas históricas de libertad e interrogando además cómo se articula con determinadas prácticas de gobierno. Así se vería que la libertad de emprendimiento no es invocada vagamente, sin mayores consecuencias o efectos en las prácticas reales. La libertad de emprendimiento, tal y como la proclaman los primeros neoliberales, es ante todo un "proyecto político", un programa de gobierno cuya realización concreta implica la movilización y transformación del entramado social entero. Desde las costumbres hasta las estructuras jurídicas, desde el ordenamiento urbano hasta la moral de un pueblo: todo puede y debe ser modificado para favorecer el emprendimiento. Los neoliberales de mediados del siglo XX señalaban la necesidad de "desproletarizar" la sociedad, convirtiendo a los obreros fabriles en artesanos y campesinos autónomos:

(...) la desproletarización industrial consiste en crear, con inteligente criterio, condiciones de vida de tipo campesino 
$y$ artesano; es decir, en una politica que procure asemejar el modo de vida y de trabajo del obrero industrial, al del artesano y campesino. Esto presupone la descentralización en toda regla de las industrias por el medio rural y las pequeñas ciudades, y una planificación rural que contrarreste las grandes aglomeraciones urbanas e industriales (Röpke 1956:281). ${ }^{10}$

Con ello se creía contribuir en la lucha contra el fascismo y el comunismo. Años más tarde, el neoliberalismo latinoamericano pretendió hacer lo propio reduciendo el sector industrial -que según los diagnósticos habría sido insuflado artificialmente por el Estado- $y$ fomentando paralelamente ciertas formas de trabajo flexible y autónomo, como el cuentapropismo y las pequeñas empresas familiares.

Allí se insertan sin duda las famosas reformas programadas por José Martínez de Hoz. Nosotros no debemos perder de vista que esas reformas parten de un diagnóstico tajante sobre los supuestos perjuicios que la mentalidad industrialista habría provocado en la sociedad argentina, incidiendo no sólo en los trabajadores y la dirigencia política, sino además en los propios miliares:

(...) los cuarenta años de adopción sistemática de esta filosofia crearon una educación económica en la población-funcionarios, empresarios, dirigentes gremiales, estudiantes e inclusive las propias Fuerzas Armadas que en 1976 se pronunciaron por su modificación-, que resulta muy difícil de erradicar. Los conceptos de 'sustitución de importaciones', 'ahorro de divisas', 'fomento de las industrias de mayor valor agregado', propios de la escuela mercantilista como criterio de industrialización dejando de lado el parámetro fundamental de la competitividad, se encuentran profundamente arraigados y provocan posturas irracionales que dificultan el proceso de modernización (Martínez de Hoz 1981:23).

Así pues, y como continuará argumentando Martínez de Hoz, las políticas de desindustrialización deben ir acompañadas por toda una reforma sobre la mentalidad misma de la población. Sin duda alguna, los programas neoliberales de desindustrialización y desproletarización han trascendido los gobiernos dictatoriales y democráticos. Hoy convendría preguntarse hasta qué punto y cómo fueron ganando la adhesión de un parte considerable de la población.
Aquí no podemos dar cifras concretas al respecto. Lo que sí podemos afirmar con algo más de certeza es que la libertad de emprendimiento, basada fundamentalmente en la capitalización personal y en la autogestión, no sólo interpela a los estratos socioeconómicos más "acomodados", sino a la población en su conjunto. De acuerdo a los programas neoliberales de gobierno, todos y cada uno deben prestarse a ser emprendedores, sin importar la procedencia socioeconómica, la ideología política o las diferentes aspiraciones de vida:

De ser el atributo de unos pocos, como lo era para Schumpeter, la actitud emprendedora -el emprendedorismodebe generalizarse al punto de ser la actitud de toda la población. En otros términos, el sistema económico capitalista necesita no sólo de algunos emprendedores, en el sentido de aquellos hombres de negocios emblemáticos de la Revolución Industrial, como un Henry Ford o un Werner Siemens, sino de un conjunto de normas y valores internalizados en la sociedad de forma tal que cada individuo sienta su trabajo como una empresa particular y su actividad laboral como el motivo principal de su vida (López Ruiz 2013:123).

Desde nuestra perspectiva, el problema no sólo está en que los programas neoliberales incumplan en la práctica con sus promesas libertarias. Lo realmente problemático es que la libertad sirva para justificar o racionalizar las situaciones más injustificables, incluyendo la producción de desigualdad, las políticas de segregación y, por supuesto, la represión. Si la población acepta que la intervención del Estado en la economía conduce inexorablemente hacia las garras del fascismo, el totalitarismo comunista o la tan remarcada catástrofe populista, entonces estará dispuesta a admitir las reformas económicas más ortodoxas y austeras, en particular aquellas que promuevan la desindustrialización y la reducción del trabajo asalariado. Si la población entiende que el acceso a mayores niveles de bienestar depende de las destrezas, los saberes y las capacidades incorporadas en individuos y grupos de individuos, entonces tolerará mejor las peores desigualdades. Si la población supone finalmente que cada cual debe mejorar su situación emprendiendo con libertad, sin verse obstaculizado por las acciones de otros individuos, entonces no sólo aceptará la represión de quienes aparezcan como un obstáculo, sino que además la solicitará a cualquier tipo de gobierno, como si la cuestión consistiese en defender a toda costa una "democracia de emprendedores".

Al neoliberalismo se lo puede analizar y problematizar desde diferentes perspectivas críticas. Una de ellas consiste en preguntar qué se hace y qué se deja de hacer en nombre de la libertad de emprendimiento. Porque en efecto, es en nombre de esa libertad que los 
gobiernos intervienen, actúan, modifican sociedades enteras y en caso necesario hacen la guerra; es también allí donde vemos que el neoliberalismo, a su manera y a través de distintos caminos, torna aceptable la violencia, los excesos y las arbitrariedades.

\section{A modo de conclusión: criticar sobre los límites del presente}

Al comenzar este artículo, señalábamos la necesidad de revisar algunas de las críticas y concepciones más vigentes sobre el neoliberalismo, particularmente aquellas que, sin detener la mirada en los matices y las variantes históricas, otorgan al fenómeno una connotación por completo "negativa". Esta connotación no resulta casual; por el contrario, su fuerte arraigamiento en nuestros modos de crítica, e incluso la dificultad para pensar más allá de sus coordenadas, provienen en parte de la necesidad de plantear una suerte de "distancia apriorística" ante el neoliberalismo. Cuando hablamos de neoliberalismo, la distancia crítica no es tomada como algo a construir mediante el análisis, sino que por lo general viene dada de antemano: "Un indicador convincente de la connotación negativa del término es que prácticamente nadie se identifica a sí mismo como un neoliberal, a pesar de que frecuentemente los estudiosos asocien a otros -políticos, asesores económicos, e incluso colegas académicos- con este término" (Boas \& Gans Morse 2009:140, traducción propia).

Ahora bien, ¿qué ganamos con acusar a los neoliberales, y junto con ellos a todos los que apoyan sus ideas y proyectos, de querer una suerte de "vuelta al pasado", ya sea en la forma de la ortodoxia económica o del intervencionismo represivo? Esa creencia quizá pueda reconfortarnos a nosotros mismos, quizá también nos permita mantener una sana distancia de las ideas que rechazamos y condenamos, pero ¿̇cuánto más aporta para la crítica y la eventual transformación de nuestro presente? Hay algo de pereza teórica y política en calificar a los contrincantes políticos como parte de un pasado, más o menos superado. Así la crítica pierde muchos de sus efectos, no llegando nunca hasta donde tiene que llegar. O lo que es todavía peor: en lugar de transformar políticamente al otro, mostrándole diferentes alternativas o realidades posibles, las críticas generan a veces el resentimiento y el endurecimiento de las posiciones ya dadas.

De donde se desprende la necesidad de modificar las coordenadas del debate. Antes que apresurarnos a decir que el neoliberalismo no va más allá de la ortodoxia económica y el intervencionismo represivo, deberíamos preguntarnos por qué los programas neoliberales triunfan a pesar de todo eso. Más allá de la ortodoxia y la represión, ¿qué permitiría al neoliberalismo ganar la adhesión de amplios sectores de la población? Esta pregunta no puede responderse desde una sola perspectiva. Nosotros nos conformamos con advertir la posibilidad de que la ortodoxia y la represión integren un programa de gobierno mucho más amplio y ambicioso, un proyecto político basado en la necesidad de desproletarizar la sociedad promoviendo a la par determinadas libertades y patrones de comportamiento. A esa idea habría que aceptarla al menos provisionalmente; de hecho, deberíamos indagar las diferentes maneras en que los programas neoliberales afectan nuestras formas de ser libres, ya sea que adhiramos o no al neoliberalismo.

Para ello habría que analizar los modos de articulación entre el neoliberalismo como programa de gobierno y las distintas libertades que actualmente podemos o no ejercer. Siguiendo una larga tradición filosófica y teórico-política, estamos acostumbrados a pensar que la libertad empieza donde terminan la atribuciones de los gobiernos y viceversa. Sin embargo, y tal como hemos intentando señalar aquí, la libertad no siempre se opone al gobierno, sino que a veces puede ser promovida por éste. Aquello que los hombres hacen o dejan de hacer en determinados momentos y contextos entra en una serie de cálculos y de estrategias políticas, como si las prácticas gubernamentales pudiesen servirse de ciertos comportamientos para perjudicar o favorecer otras acciones posibles. Se trata de dirigir las conductas de los individuos hacia unos objetivos gubernamentales específicos; o, en otras palabras, de gobernarlos a través de sus distintas acciones y reacciones, de sus deseos y aspiraciones, definiendo así sus libertades o sus modos de comportamiento. ${ }^{11}$

¿De qué manera el neoliberalismo nos hacer ser libres? ¿a qué precio? ¿con qué formas de violencia como contraparte? ja costa de qué otras libertades posibles? Estas son algunas de las preguntas que desde ahora y en delante habría que plantearse, sin creer que, cuando se trata de neoliberalismo, ya todo está más o menos dicho. No hay una sola crítica al neoliberalismo, así como tampoco hay críticas que sean a priori más efectivas que otras. Antes bien, la efectividad de la crítica debe construirse mediante un análisis paciente y riguroso, capaz de incluir las distintas variables y los diversos matices que hacen al problema.

Indudablemente, resulta difícil elaborar una crítica que vaya más allá de las denuncias habituales de ortodoxia económica y de represión estatal. De alguna manera, es como llegar a un punto límite donde nos vemos obligados a inventar nuevos nombres, nuevos conceptos, nuevos análisis e interpretaciones. Ahí reside la importante tarea que enfrentan las ciencias sociales de nuestros tiempos: en dar la suficiente densidad conceptual y teórica al fenómeno del neoliberalismo. Lo que subyace a esa tarea no es un mero afán académico o erudito; es ante todo la necesidad de afinar cada vez más la crítica política. 
' Como aclaran Boas y Gans-Morse, tras las experiencias dictatoriales de las décadas de 1970 y 1980, gran parte de los estudios latinoamericanos ha reducido al neoliberalismo a una política económica de ajuste:" "Lo estudiosos suelen caracterizar tres conjuntos de políticas neolber eliminando los controles de precios, desregulando los mercados de capitales, y la reduciendo las barreras al comercio; aquellos que reducen el papel del Estado en la economía, principalmente a través de la privatización de las empresas estatales; y aquellos que contribuyen a la austeridad fiscal y la estabilización macroeconomica, incluyendo el control estricto de la oferta monetaria, la eliminación de los déficit presupuestarios y la reducción de las subvenciones del gobierno" (Boas y Gans-Morse 2009:143; traducción del autor).

" calculadas y razonadas y según las cuales se debe organizar las instituciones, ordenar los espacios, regular los comportamientos. Estos programas jamás pasan en su totalidad a las instituciones, sino que se simplifican, o se eligen algunos y no otros, y esto nunca ocurre como estaba previsto" (Foucault 1994:27-28, traducción propia). El punto de partida está en el curso Naissance de la biopolitique de Foucault, dictado en 1979 y publicado recién en el año 2004. Desde entonces, varios estudios críticos continuarían con la genealogía propuesta.Véase por ejemplo Jamie Peck (2008), Laval y Dardot (2013) o William Davies (2014) entre otros.

Los nombres y las corrientes de pensamiento mencionadas tienen relación con la historia incipiente del neoliberalismo en Argentina y otros paises de America Latina, aunque no lo parezca a simple vista. Desde mediados del siglo XX las mismas fueron repensadas y contextualizadas por muchos economistas, intelectuale y formadores de opinión locales, incluso antes de tomar contacto con la hoy famosa "Escuela de Chicago" (Gencos

2015b). 2015b). La idea de una continuidad entre el intervencionismo estatal, el colectivismo y el totalitarismo se de 1940 y traducido inmediatamente al español como La crisis del colectivismo (Röpke 1949b).

"Como sugirió Foucault muy tempranamente, a propósito de los programas neoliberales aquí analizados: "la intervención gubernamental debe ser discreta a nivel de los procesos económicos mismos o, por el contrario, debe ser masiva cuando se trata de este conjunto de datos técnicos, científico, jurídicos, demográficos, digamos en general sociales, que ahora serán cada vez más objeto de la intervención gubernamental" (Foucault

2004:147, traducción propia).
7 La genealogía del neoliberalismo en Argentina no debería prescindir del nombre de Ricardo Zinn, a quien se considera como uno de los principales artífices del "Rodrigazo" (1975), además de haberse desempeñado como directivo del Grupo Mari Según el diagnóstico propuesto por Zinn en el libro La segunda fun con de la república (1976), la Arrentina ha sufrido un profundo proceso de "decadencia" que comienza con he sanción del sufragio universal en 1912 y que alcanza su paroxismo con el "populismo desenfrenado" de la experiencia peronista. Lo llamativo es que, en esa misma línea argumentativa la decadencia debe resolverse mediante "crisis" como mecanismo de purificación y redención de todo el sistema económico, eliminando particularmente aquellos sectores que viven a expensas del proteccionismo estatal y las demás permisividades del populismo. Para un analisis sobre el pensamiento y la trayectoria de Ricardo Zinn, véase Grondona (2011) y Vicente (2013).

Utilizamos la expresión "condiciones de aceptabilidad", tomada del vocabulario de Michel Foucault, par indicar la constelación de factores que, en determinados lugares y momentos históricos, facilita la aceptación de un orden de cosas que en principio resultaría inaceptable, convirtiéndolo de hecho en la realidad más manera, que detrás de su aparente "naturalidad" está la arbitrariedad, la violencia el error o el accidente:"La identificación de la aceptabilidad de un sistema es inseparable de la detección de lo que lo hacía dificil de aceptar: su arbitraria en términos de conocimiento, su violencia en términos de poder, en suma, su energía" (Foucault: 1990:50, traducción propia).

Según los análisis de economistas como Ludwig von Mises (1968),Theodore Schultz (1961) o Gary Becker (1983), los recursos de los trabajadores son siempre un "capital humano", vale decir, un capital basado en las capacidades y las habilidades que posee o podria poseer ctalquier ser humano. Ese capital no sólo depende, como es de por si evidente, del nivel de escolurizaciorn y capacitación de cado hindwidno, sino adenás de su estado de salud, sus habitos y costumbres, sus experiencias vividas e incluso de la crianza familiar (Becker: Latina, véase López Ruiz (2007 y 2013).
${ }^{10}$ En Méndez (2014 y 2017), brindamos un análisis más detallado sobre la programación neoliberal de las políticas de desproletarización.

${ }^{11}$ Esta perspectiva de análisis ha sido identificada con el concepto de "racionalidad de gobierno" propuesto por Foucault en la década de 1970. La racionalidad incluye los saberes, las estrategias y las técnicas mediante las cuales resulta posible articular la libertad de los individuos con determinados objetivos de gobierno (Foucault 1994b; Foucault 1988). Se encontrara un estudio introductorio sobre concepto de racionalidad de gobierno en Gordon (1991). Puesto en estos términas, d neoliberalismo no es sólo un puñado de recetas económicas aplicables mediante la represión o el acallamiento de la disidencia, sino también un programa específico de prácticas destinada a producir y gobernar nuestras libertades. De ahí que el neoliberalismo aparezca como algo más amplio y más

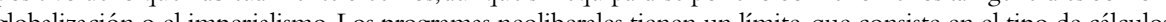
estrategias y prácticas que promueven; ese límite es justamente su racionalidad. 


\section{Referencias}

Becker, Gary (1983) Capital humano: un análisis teórico y empírico referido fundamentalmente a la educación. Madrid: Alianza.

Becker, Gary (2013) "Meritocracies and Intergeneration Mobility". The Becker-Posner Blog http://www.becker-posner-blog.com/2013/01/meritocracies-and-intergeneration-mobility-becker.htm] acceso el 3 de abril de 2017.

Boas, Taylor y Gans-Morse, Jordan (2009) "Neoliberalism: From New Liberal Philosophy to Anti-liberal Slogan”. Studies in Comparative International Development, 44(2):137-161.

Boron, Atilio (2003) "La sociedad civil después del diluvio neoliberal”. En Emir Sade y Pablo Gentili (comps.) La trama del neoliberalismo. Mercado, crisis y exclusión social. Buenos Aires: CLACSO: 51-92.

Brenner, Neil, Peck, Jamie y Theodore Nik (2010) "Variegated neoliberalization: geographies, modalities, pathways". Global Networks 10(2):182-222.

Bresser-Pereira, Luiz C. (2009) "El asalto al Estado y al mercado: neoliberalismo y teoría económica”. Nueva Sociedad, (221):83-99.

Bourdieu, Pierre (1998) "L'essence du néolibéralisme". Le monde diplomatique. https://www monde-diplomatique.fr/1998/03/BOURDIEU/3609 acceso el 15 de marzo de 2017.

Davies, William (2014) The Limits of Neoliberalism. Authority, Sovereignty and the Logic of Competition. Londres: SAGE.

Eucken, Walter (1956) [1939-1950] Fundamentos de política económica. Madrid: Rialp.

Eucken, Walter (1947) [1939] Cuestiones fundamentales de la economía política. Madrid: Revista de Occidente.

Foucault, Michel (2013) [1983] "Acerca de la genealogía de la ética. Un panorama del trabajo en curso". En La inquietud por la verdad. Escritos sobre la sexualidad y el sujeto. Buenos Aires: Siglo XXI:195-223.

Foucault, Michel (2004) Naissance de la biopolitique. Paris: Seuil/Gallimard.

Foucault, Michel (1994a) "La pussière et le nuge”. En Dits et Écrits IV (1980-1988). Paris: Gallimard:10-37.
Foucault, Michel (1994b) "« Ommes et singulatim »: vers une critique de la raison politique”. En Dits et écrits IV. Paris: Gallimard:134-161.

Foucault, Michel (1990) "Qu'est-ce que la Critique [Critique et Aufklärung]". Bulletin de la Société française de Philosophie, 2:35-63.

Foucault, Michel (1988) "The political technology of individuals". En Technologies of Self. A Seminar with Michel Foucault. Amherst: University of Massachusetts Press:145-162.

Foucault, Michel (1971) "Nietzsche, la généalogie, l'histoire". En AA.VV Hommage a Jean Hyppolite. Paris: Presses Universitaires de Frances:145-172.

Gómez, Ricardo (2014) Neoliberalismo, fin de la historia y después. Buenos Aires: Punto de Encuentro.

Gómez, Ricardo (1995) Neoliberalismo y seudociencia. Buenos Aires: Lugar Editorial.

Gordon, Colin (1991) “Governmental Rationality: an introduction”. En Graham Burchell, Colin Gordon y Peter Miller (Eds.) The Foucault Effect. Chicago: University of Chicago Press:1-51.

Grondona, Ana L. (2013) "Las voces del desierto. Aportes para una genealogía del neoliberalismo como racionalidad de gobierno en Argentina (1955-1975)". Revista del CCC, 13(5):1-23.

Haidar, Victoria (2016) "Sociedad de masas: lecturas procedentes del ordoliberalismo y de la Escuela de Frankfurt”. Sociológica, 31(88):29-64.

Harvey, David (2015) Breve historia del neoliberalismo. Buenos Aires: Akal.

Hayek, Friedrich A. (2011) [1944] Camino de servidumbre. Madrid: Alianza.

Jessop, Bob (2002) The Future of the Capitalist State. Cambridge: Polity Press.

Laval, Christian y Dardot, Pierre (2013) La nueva razón del mundo. Ensayo sobre la sociedad neoliberal. Barcelona: Gedisa.

López Ruiz, Osvaldo (2013) "La 'empresa' como modo de subjetivación”. Revista Confluencia, 6(13):119-145. 
López Ruiz, Osvaldo (2007) “Ethos empresarial: el 'capital humano' como valor social”. Estudios Sociológicos, XXV(74):399-425.

Martínez de Hoz, José A. (1981) Bases para una Argentina moderna 1976-1980. Buenos Aires: Edición del autor.

Méndez, Pablo M. (2017) 'Wilhelm Röpke y la espiritualidad del neoliberalismo', Astrolabio. Nueva época, 18:112-146.

Méndez, Pablo M. (2015a) "Foucault y la Aufklärung, o el trabajo de sí como legado crítico". Cuestiones de Filosofía, 17:139-162.

Méndez, Pablo M. (2015b) "La fobia al Estado como remedio espiritual. Incisiones foucaultianas sobre el neoliberalismo". Perspectivas Metodológica, 1(15):23-33.

Méndez, Pablo M. (2014) "El sujeto económico del neoliberalismo. Aportes y discusiones para una nueva "ontología del presente". Hybris. Revista de filosofía, 5(1):33-55.

Mises, Ludwig (1968) La acción humana:Tratado de economía. Madrid: Sopec.

Müller-Armack, Alfred (2011) [1956] “Economía social de mercado”. En AA.VW., Una mirada a la teoría, a los modelos económicos y a la economía social del mercado. Reflexiones teóricas para Bolivia. La Paz: Konrad Adenauer Stiftung:15-19.

Müller-Armack, Alfred (1962) [1959] "Estudios sobre la economía social de mercado”. Revista de Economía y Estadística, Tercera Época, 6(4):173-221.

Peck, Jamie (2008) "Remaking laissez-faire". Progress of Human Geography, (32)1:3-43.

Röpke, Wilhelm (1960) Economía y Libertad. Buenos Aires: Foro de la libre empresa.

Röpke, Wilhelm (1956) [1942] La crisis social de nuestro tiempo. Madrid:Revista de Occidente.

Röpke, Wilhelm (1949a) [1944] Civitas humana. Cuestiones fundamentales en la reforma de la sociedad y de la economía. Madrid: Revista de Occidente.

Röpke, Wilhelm (1949b) La crisis del colectivismo. Emecé: Buenos Aires.

Saad-Filho, Alfredo y Johnston, Deborah (2005) Neoliberalism. A critical reader. London: Pluto Pres.
Schultz, Theodore W. (1961) "Investment in human capital". The American Economic Review, 51(1):1-17.

Thatcher, Margaret (1981) 'Economics are the method: the object is to change the soul'. Sunday Times (03/04/1981) http://www.margaretthatcher.org/document/104475 acceso el 15 de marzo de 2017.

Vargas Llosa, Mario (2014) "Venezuela se equivocó con Chávez como Alemania con Hitler”. La Nación (20/04/2014) http://www.lanacion.com.ar/1684798-mario-vargas-llosa-venezuela-se-equivoco-con-chavez-como-alemania-con-hitler acceso el 10 de julio de 2017.

Venugopal, Rajesh (2015) “Neoliberalism as concept”. Economy and Society, 44(2), 165-187.

Vicente, Martín (2013) “¿La tercera fundación de la República? Ricardo Zinn y las lógicas de la transformación neoliberal en la Argentina (1975-1995)". Jornada: "Recuperando trayectorias intelectuales en el Estado. Argentina en la segunda mitad del siglo XX" http://www.ungs.edu.ar/ ms_idh/wp-content/uploads/2014/07/Vicente.pdt acceso el 2 de julio de 2017.

Wacquant, Loïc (2012) "Three steps to a historical anthropology of actually existing neoliberalism”. Social Anthropology, 20(1):66-79.

Zinn, Ricardo (1976) La segunda fundación de la república. Pleamar: Buenos Aires.

\section{Cómo citar este artículo}

Méndez, Pablo Martín (2017) "El neoliberalismo puesto en perspectiva. Para una revisión de nuestras concepciones críticas”. Revista Perspectivas de Políticas Públicas vol. 7 №13. 